\title{
Factors that influence knowledge management systems to improve knowledge transfer in local government: A case study of Buffalo City Metropolitan Municipality, Eastern Cape, South Africa
}

\begin{tabular}{|c|c|}
\hline \multicolumn{2}{|c|}{$\begin{array}{l}\text { Authors: } \\
\text { Samuel S. Ncoyini }{ }^{1} \text { (1) } \\
\text { Liezel Cilliers }^{1} \text { (1) }\end{array}$} \\
\hline \multicolumn{2}{|c|}{$\begin{array}{l}\text { Affiliations: } \\
\text { 'Department of Information } \\
\text { Systems, Faculty of } \\
\text { Management and Commerce, } \\
\text { University of Fort Hare, East } \\
\text { London, South Africa }\end{array}$} \\
\hline \multicolumn{2}{|c|}{$\begin{array}{l}\text { Corresponding author: } \\
\text { Samuel Ncoyini, } \\
\text { sncoyini@ufh.ac.za }\end{array}$} \\
\hline \multicolumn{2}{|c|}{$\begin{array}{l}\text { Dates: } \\
\text { Received: } 06 \text { Dec. } 2018 \\
\text { Accepted: } 09 \text { Oct. } 2019 \\
\text { Published: } 22 \text { July } 2020\end{array}$} \\
\hline \multicolumn{2}{|c|}{$\begin{array}{l}\text { How to cite this article: } \\
\text { Ncoyini, S.S., \& Cilliers, L. } \\
\text { (2020). Factors that influence } \\
\text { knowledge management } \\
\text { systems to improve } \\
\text { knowledge transfer in local } \\
\text { government: A case study of } \\
\text { Buffalo City Metropolitan } \\
\text { Municipality, Eastern Cape, } \\
\text { South Africa. SA Journal of } \\
\text { Human Resource } \\
\text { Management/SA Tydskrif vir } \\
\text { Menslikehulpbronbestuur, } \\
\text { 18(0), a1147. https://doi. } \\
\text { org/10.4102/sajhrm. } \\
\text { v18i0.1147 }\end{array}$} \\
\hline \multicolumn{2}{|c|}{$\begin{array}{l}\text { Copyright: } \\
\text { (c) 2020. The Authors. } \\
\text { Licensee: AOSIS. This work } \\
\text { is licensed under the } \\
\text { Creative Commons } \\
\text { Attribution License. }\end{array}$} \\
\hline \multicolumn{2}{|l|}{ Read online: } \\
\hline 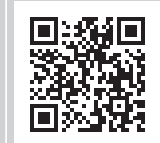 & $\begin{array}{l}\text { Scan this QR } \\
\text { code with your } \\
\text { smart phone or } \\
\text { mobile device } \\
\text { to read online. }\end{array}$ \\
\hline
\end{tabular}

Orientation: The demand for improved service delivery requires new approaches and attitudes from local governments. The lack of knowledge management (KM) and, therefore, a low level of information and knowledge transfer in the public services were identified as two of the main contributors to poor service delivery.

Research purpose: The purpose of this research study was to gain an in-depth understanding of the factors that impact on KM systems to improve the knowledge transfer at Buffalo City Metropolitan Municipality (BCMM).

Motivation for the study: A lack of institutional capacity in local government is one of the primary reasons why service delivery is still an issue in almost all of South Africa's provinces. A Knowledge management system (KMS) would enable BCMM to build up organisational knowledge through the systematic capture and organisation of the wealth of knowledge and experience of staff, stakeholders, clients, partners and beneficiaries. AKMS leverage knowledge that already exists within and outside BCMM and can make this knowledge readily accessible to the Municipality employees.

Research approach/design and method: Qualitative data were collected by means of semi-structured interviews and a convenience sampling technique from five participants. The qualitative interviews were analysed by means of thematic analysis to analyse the data.

Main findings: The study found that the KM culture within the municipality is not supportive as the hierarchical and bureaucratic management supresses any attempts at openness and support. At the human resources level, information is not seamlessly transferred between managers and their subordinates. There seems to be a culture of knowledge hoarding in an attempt to augment personal importance or worth.

Practical/managerial implications: To solve the knowledge transfer problems, KM must be aligned with the organisational strategy. Official KM strategies must be developed and aligned to organisational strategies to ensure that the top management makes and shares a plan for a vision of continuous knowledge transfer.

Contribution/value-add: The study therefore recommends that BCMM must ensure that knowledge transfer practices and initiatives are fully supported and promoted by the top management. This will ensure that sufficient resources are allocated to support knowledge transfer.

Keywords: knowledge transfer; knowledge management systems; local government; public services; Buffalo City Metropolitan Municipality.

\section{Introduction}

We live in a world where knowledge has become a vital commodity (Ansari, Youshanlouei, \& Mood, 2012). Organisations that depend on their knowledge assets rather than their physical assets are expected to be more sustainable in the future, as they have accepted knowledge as a strategic resource that is crucial for their competency and stability within a competitive environment. Knowledge can be a valuable asset, but organisations have to manage it appropriately by prioritising systems for creating, storing, transferring and employing knowledge within the organisation (Ansari et al., 2012). 
Ondari-Okemwa and Smith (2009) stated that lack of knowledge management (KM) and therefore a low level of information and knowledge transfer (KT) in the public services have been identified as two of the main contributors to poor service delivery. Munzhelele (2012) also argued that the implementation of $\mathrm{KM}$ is one of the factors that will impact on the improvement of service delivery.

The demand for improved service delivery requires new approaches and attitudes from the local government. One of the ways in which this can be achieved is to focus on continuous improvement by driving innovation and lessons learnt from the municipalities' past successes and failures (Kitchin, Ovens, \& Turpin, 2013). Etherington (2013) believed that for local government authorities to rethink service delivery, they need to find better ways to share information assets, business processes and staff expertise with their citizens and business partners. Munzhelele (2012) indicated that the implementation of KM is one of the factors that will impact on the improvement of service delivery, as it will improve institutional capacity. Dikotla, Mahlatji, Makgahlela and Africa (2014) stated that government employees do not share their knowledge and experience as their counterparts do in the private sector. A knowledge audit process conducted at Buffalo City Metropolitan Municipality (BCMM) in 2010 revealed a lack of integrated information technology (IT) infrastructure that limits the flow of information (Kitchin et al., 2013). Knowledge transfer has been found to be limited in the municipality, and staff members found it difficult to share their knowledge with their colleagues. Knowledge transfer using knowledge management systems (KMSs) enables local government employees to acquire and understand the proper knowledge that will influence the quality of service delivery. The transfer of knowledge is fundamental to the process of learning.

\section{Research purpose and objective}

The main purpose of this research study is to gain an indepth understanding of the factors that impact on KMSs to improve the KT at BCMM. The research study focusses on KT within the municipality as the general area of research. Knowledge transfer is critical in local government because of its contribution to knowledge application, innovation and competitive advantage (Wang, Noe, \& Wang, 2014). Therefore, the objective of this study is to produce critical success factors (CSFs) that will improve KMS and KT among employees at BCMM, which will ultimately improve service delivery. In particular, this research attempts to answer the following question: What factors will impact on KMSs to improve $\mathrm{KT}$ in BCMM?

The rest of the article is structured as follows: The next sections discuss the importance of KT in a municipality followed by the role of KMSs to improve the transfer of knowledge. Then, the methodology that was used in the study will be discussed, followed by the analysis of the results and a discussion thereof.

\section{Literature review Knowledge transfer in local government}

Knowledge has been recognised as the primary driver of an organisation's growth and competitive advantage (Wang, Lee, \& Lim, 2009). Assegaff and Hussin (2012, p. 130) asserted that 'knowledge is believed as a potential asset that could bring sustainable competitive advantages for organisations. To gain value from the knowledge, an organisation should be able to manage it effectively.' An approach implemented by organisations to manage their knowledge is recognised as KM. Therefore, organisations are becoming more interested in implementing KM programmes to manage their knowledge resources. Knowledge management systems are used to support and improve the processes of knowledge generation, sharing, storage and application (Wang et al., 2009).

The formation of knowledge involves the transformation of data into information and information into knowledge, which finally develops into wisdom (Gaffoor \& Cloete, 2010). Scientific data are objective facts that describe an event without any judgement, perspective or context, and it becomes information when meaning is added to it (Mohamed, 2014). Information is the result of processed and structured data, and it can be transferred into knowledge by means of connections, comparisons, conversations and consequences. Knowledge derives from information, which is anchored in the beliefs, views and obligations of its holders (Ramdhania, 2012).

Knowledge transfer involves knowledge being transferred or disseminated throughout the organisation. As a process, KT involves the contribution of knowledge by the organisation and the collection, application and assimilation of knowledge by employees (Van Der Meer, 2014). The value of knowledge grows and increases as it is shared within an organisation. When employees use knowledge, they add more insights to it and refine it further, thereby adding more value. When knowledge is used, it grows; but when not used, it diminishes (Teimouri, Emami, \& Hamidipour, 2011) - this means that knowledge will keep growing whenever employees share what they know; when employees transfer their knowledge, they do not lose it. Knowledge transfer requires the preparedness of an individual or a group to work with others and share knowledge to their mutual benefit. When knowledge is not shared within an organisation, it is nearly impossible for it to be transferred to other employees. This indicates that KT will not happen in an organisation except if the employees and teams exhibit a high level of co-operative behaviour (Teimouri et al., 2011).

The goal of KT in local government organisations is to improve decision-making among employees so as to improve service delivery and achieve business goals through the sharing of knowledge between the municipality and citizens (Mohamed, 2014). Knowledge transfer improves organisational learning, which, in turn, improves service delivery, by reducing customer response times (Van Der Meer, 2014). If municipalities share knowledge with external 
organisations, they can develop their own knowledge bases and thus improve innovation. Municipalities can access different fields of expertise, competencies and capabilities that may be costly or unobtainable through other avenues (Van Der Meer, 2014).

The South African public sector is making use of the sectoral network that was created by the Department of Public Service and Administration. The sectoral network aims to enhance the model of a client-centred public service sector by applying the 'Batho Pele' principles (Mothamaha \& Govender, 2014). This ideal of a client-centred public service sector was endorsed by the South African government, which had created several initiatives based on its client-centred philosophy. During the mid-1990s, the international public sector reform policies that stemmed from the 'New Public Management' (NPM) theory placed an emphasis on the South African public sector's performance with regard to financial efficiency and budget parameters (Mothamaha \& Govender, 2014).

Considering the above influences, it is apparent that the South African public sector functions in a business-like style where the central idea of service provision is to respond to the needs of the citizens and provide inclusive and integrated service delivery (Dikotla et al., 2014; Gaffoor \& Cloete, 2010). This means that they have to adopt the idea of KT as a mechanism of achieving a competitive advantage by making use of human and intellectual resources within their organisations. Dikotla et al. (2014) differed from Gaffoor (2008), arguing that although KT has been seen as a mechanism of improving municipal governance, the majority of South African municipalities do not have formal functional KM programmes in place. Knowledge-sharing (KS) culture does exist within individual municipalities but not across all the municipalities. Those municipalities that perform well do not share their best practices with the underperforming ones (Dikotla et al., 2014).

In South Africa, KM has become a priority within the local government context (Gaffoor \& Cloete, 2010). Knowledge management has been recognised by South Africa's Provincial and Local Government Departments as a strategic management skill for local government senior management personnel. Gaffoor and Cloete (2010,p.5) contend that 'at local government level, cognisance must be taken of the fact that South African municipalities function in an environment characterised by greater uncertainty and competition than in the past.'

In South Africa, there are legal frameworks in place that regulate the legal aspects of KM. The Intergovernmental Relations Framework Act of 2005 has influenced local government to ensure that a coherent system for KS is in place (MILE, 2010). According to this act, local government organisations should take all reasonable steps to ensure that they have the institutional capacity and effective processes to consult, collaborate and share information with the other organs of the state.

More legal frameworks that arise from the Bill of Rights include the Promotion of Access to Information Act of 2013 (PAI) and the
Electronics Communications Act of 2005. The primary objective of the PAI Act is to influence the constitutional right of access to any information held by the government, and by any other person who is necessary for the application or protection of any rights (Gaffoor, 2008). The PAI Act ensures that good governance, transparency and accountability are exercised to promote better decision-making and participation. The Electronics Communications Act of 2005 provides a regulatory framework for South African electronic communications (Gaffoor, 2008). The act provides for research and development within the information and communication technology (ICT) sector. The act further provides for information security and reliability of networks.

A report by the South African Local Government Association (SALGA) reported that the BCMM was the first South African municipality to appoint political KM champions (SALGA, 2015). The municipality also conducted KM training for councillors, senior and middle management, as well as departmental KM champions, in terms of the KM strategy and framework. Knowledge Management Reference Group (KMRG) identified BCMM's councillor training as a best practice that must be used as the basis for training councillors in other municipalities and members of both parliament and provincial legislatures (SALGA, 2015).

The success of KS cannot be measured without taking into account the culture of the environment in which the sharing takes place. Cultural concerns, such as leadership, trust, reward and communication, may impact negatively or positively on KS between and within municipalities (Deverell \& Burnett, 2012). A KS culture may then be thought to be one in which the influence and importance of such issues for enabling or preventing KS are acknowledged and addressed. As prominence has been given to the need for effective KS practices and to the value of intellectual capital within organisations, it would be advantageous to promote a KS culture within municipalities (Schutte \& Barkhuizen, 2014). Because of the increasing interdependencies between job expectations and the information explosion, many local government officials, if given a chance, have knowledge (know-how) that could add some value to the institution. Municipalities that embrace a culture that restrains KS will never be able to create a competitive edge, as KS is believed to be significant in creating and leveraging knowledge assets. A KS culture is thus imperative for the South African municipalities, in order to distinguish them as institutions of service (Schutte \& Barkhuizen, 2014).

\section{The role of knowledge management systems infrastructure in knowledge transfer}

Knowledge management involves the transfer of knowledge, while technology is used to search, store, retrieve and access information. According to Tan and Noor (2013), the infrastructure of KMS facilitates the transfer of knowledge by employees. Knowledge management systems are technologysupported information systems that help to document, transfer and distribute the tacit and explicit knowledge between 
employees to improve organisational efficiency (Wang et al., 2014). The role of KMS infrastructure includes supporting collaboration, communication and the search for information and knowledge. Becerra-Fernandez and Sabherwal (2010) indicated that IT facilitates, shares and accelerates knowledge growth. A KMS makes use of a variety of KM technologies and mechanisms to support the KM processes.

The objective of a KMS is not to manage all the available knowledge within the organisation but to facilitate selected knowledge being managed and made available to assist employees to create, store and transfer or share it within the organisation (Greco, Grimaldi, \& Hanandi, 2013). The types of KMSs include customer relationship management systems, decision support systems, document management systems, knowledge portal systems, eLearning platforms, supply chain management systems, virtual human resource management systems and artificial intelligence (Becerra-Fernandez \& Sabherwal, 2010; Greco et al., 2013). To store knowledge, South African municipalities make use of IT-based tools and systems that enable KM to fulfil their goals (Kitchin et al., 2013). These tools consist of groupware systems, Intranet, content and document management systems, and data warehousing and mining. Directories of experts are also used by South African municipalities to help employees find who have expertise or knowledge for a particular project or task. These directories also help employees to seek guidance from other employees in other organisations (Kitchin et al., 2013).

\section{Factors that affect employees' attitudes towards knowledge management systems}

As knowledge is personal, created and developed by employees, the sharing of it is important for its development, distribution and management at all higher levels. Knowledge cannot be shared without the participation of the employee, which requires learning (Duan, Nie, \& Coakes, 2010). The recent developments in ICT have resulted in many public organisations adopting ICT-based KMSs to support their employees' KT, and they are engaging in virtual communities of practice (CoP) (Zhang, Vogel, \& Zhou, 2012). Contrary to the expectations, organisations are facing serious problems as these ICT-supported KT projects have high failure rates. Zhang et al. (2012) stated that KMSs are more prominent in improving $\mathrm{KT}$ in large units with routine tasks and that junior employees have a good attitude towards making use of communication tools to share their knowledge.

Individual factors, such as attitude, self-efficacy, motivation, trust and reciprocity, influence the local government employees' intentions to share knowledge (Amayah, 2013; Seba, Rowley, \& Lambert, 2012; Tamjidyamcholo, Bin Baba, Tamjid, \& Gholipour, 2013). A study by Tamjidyamcholo et al. (2013) showed that attitude is found to have the biggest influence on an employee's intention to participate in KT. Attitude also plays a critical role in employees' intentions to share their knowledge as those that are positive towards KT will be more motivated to participate in $\mathrm{KT}$ activities.
Knowledge cannot be transferred effectively if employees are not motivated to share it (Amayah, 2013). A high level of selfefficacy in an employee encourages self-confidence about the skills and abilities, and it also strengthens motivation (Tamjidyamcholo et al., 2013). The high level of trust among the employees encourages their attitudes towards KS (Seba et al., 2012).

Kathiravelu, Mansor and Kenny (2013) investigated factors that influence KS behaviour among Malaysian public service employees. Their study revealed that organisational influences have a direct bearing on employees' KS behaviour. Lee and Hong (2014) examined the factors that affect hospital employees' KS intentions, KS behaviour and innovation behaviour. They found that organisational factors and individual factors significantly influence KS intentions.

An effective organisational culture for KM entails practices and norms that inspire the transfer of information across department lines and between employees (Theriou et al., 2011). Within local government, organisational culture can perform four functions. Organisational culture provides employees with organisational identity, encourages social system stability, facilitates collective commitment and forms the behaviour by helping employees to make sense of their surroundings (Mannie, Van Niekerk, \& Adendorff, 2013). A collaborative culture is a key aspect for KS among teams and employees because the process of transferring knowledge requires employees to come together to discuss, interact and share knowledge (Sedighi \& Zand, 2012).

Wang and Noe (2010) found that for KT to occur, top management support has been shown to be positively linked with employees' perceptions of a KS culture and preparedness to share knowledge. Support from top management affects both the quality and level of KT through influencing employee commitment to KM. Perceived supervisor and coworkers' support and their inspiration for KT also increase employees' knowledge exchange and their perceptions of usefulness of the sharing of knowledge.

The hierarchical structures in local government organisations have an impact on employees with whom each employee normally relates and from or to whom the employee is expected to transfer knowledge (Becerra-Fernandez \& Sabherwal, 2010). Reporting structures encourage the flow of data and information and the nature of teams who make decisions together. As a result, the creation and sharing of knowledge may be positively or negatively affected. In more decentralised organisations with larger groups of employees, KS is more likely to occur (Becerra-Fernandez \& Sabherwal, 2010). The flexibility of the organisational structure inspires collaboration and sharing of knowledge within the organisation (Sedighi \& Zand, 2012).

\section{Theoretical framework}

The socio-technical systems (STS) theory (see Figure 1) was used in this study as a theoretical framework to explain social and technical dimensions that affect employees' 


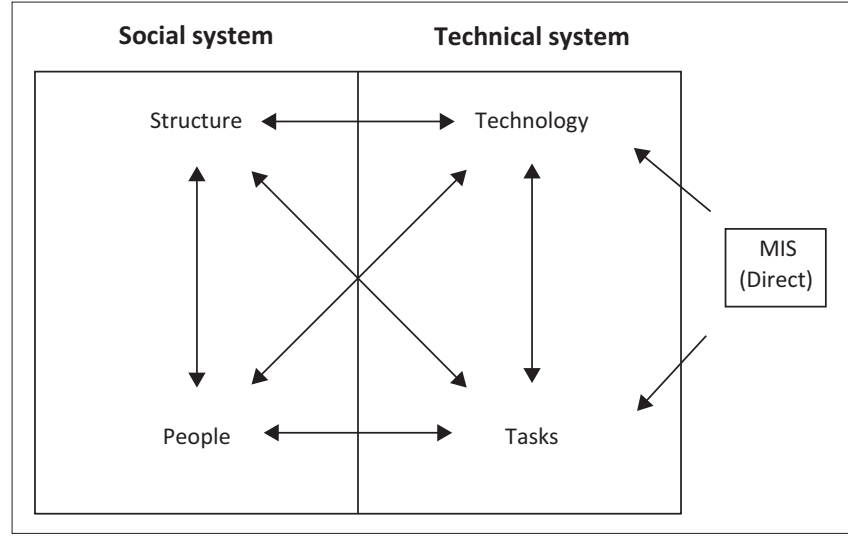

Source: Cartelli, A. (2007). Socio-technical theory and knowledge construction: Towards new pedagogical paradigms? Issues in Informing Science and Information Technology, 4, 2-14 FIGURE 1: Socio-technical systems theory.

intentions to share knowledge within the BCMM. The motivation behind examining information system problems, using both the social and technical dimensions, was to describe organisational aspects that are a combination of social and technological subsystems in the operational activities (Assegaff \& Hussin, 2012).

The technological approach focusses on technical and technological aspects of KM. The technological approach is centred on the collection, storage, categorisation and use of knowledge using technical systems. Technical systems consist of email, groupware, intranet, databases and others (Sajeva, 2010). The technological approach is a system strategy focussing on the codification of knowledge within the KM processes. This strategy concentrates on the codification and storage of knowledge through IT and attempts to share knowledge formally.

The social approach to KM acknowledges that knowledge is subjective. Knowledge predominantly exists in the minds of employees and is shown through social interactions. In contrast to the technological approach to KM, social-based KM stresses that knowledge can be attained and shared through socially interactive processes, such as experts, reciprocal relationships and trust among employees, to support KM activities (Sajeva, 2010).

\section{Research design}

The interpretive paradigm was considered appropriate for the study, as qualitative data were collected and used to inductively interpret the attitude and behaviour of BCMM employees towards KT. In this study, a case study design was utilised to produce CSFs that would improve KMS and KT among employees at BCMM, which would ultimately improve service delivery. Yin (2014) defined a case study as a first-hand investigation focussing on an existing phenomenon within its real-life environment, and boundaries between phenomenon and its environment are not clearly evident. Case studies are thus suitable for studying complex social phenomena, as this case study seeks to investigate the complex KMSs in the BCMM and how the employees make use of these systems to share knowledge.

\section{Research setting}

The BCMM is a Category A municipality located on the east coast of the Eastern Cape Province, South Africa. The municipality's administration is headed by the city manager, who is supported by the heads of directorates who, in turn, work with officials to execute the resolutions of the council as well as programmes and activities of the organisation. During 2015 and 2016, the municipality underwent organisational restructuring. The aim was to align the organisational structure to strategic planning, the operational and budgetary planning processes.

The departments under the Directorate: Office of the City Manager include Governance and Internal Auditing; Chief Operating Office; Information Technology; Legal Services and Municipal Court; Enterprise Project Management; Information, Knowledge Management, Research and Policy; and Expanded Public Works Programme.

The Information, Knowledge Management, Research and Policy (IKM, Research and Policy) Department reports directly to the city manager. The department or unit is responsible for coordinating and facilitating the municipality's four core functions that are information management, KM, research and policy. The management job roles in the department are:

- head: IKM, research and policy

- manager: research and policy

- manager: KM and innovation (during the interviews, this position was vacant, and research and policy manager was acting as the manager of the KM section).

\section{Research participants and sampling methods}

For this study, the population identified included the employees of BCMM in East London. With regard to the sampling of participants, a convenience sampling technique was used to determine the participants who were available and had the appropriate understanding or experience to contribute meaningfully to the study (De Vos, Strydom, Fouche, \& Delport, 2011). Five participants were interviewed from the ICT and KM units. The five participants interviewed were aged between 30 and 50 years, and there were three male and two female participants. Two participants had recently joined the municipality as they had worked less than a year in their departments. One participant had worked between 3 and 5 years, while another had worked between 5 and 10 years. There was one participant who had worked for the municipality for more than 10 years.

\section{Data collection methods}

Primary and secondary data were collected. The primary data were collected using interviews. The use of semistructured interviews with open-ended questions allowed the participants to expand on responses and enabled further probing by the researcher when necessary. The interview 
questions were structured to include different sections following themes from the literature reviewed:

- organisational culture and KT

- top management support and KT

- the role played by effective KM

- motivation and KT

- use of IT infrastructure for KT

- barriers to effective KM implementation.

Secondary data were collected using a literature review from academic journals, books in both print and electronic formats, conference proceedings, relevant websites and theories relating to this study. Electronic databases, such as ACM Digital Library, Sage Online Journals, Science Direct, Springer Link and African Journals, were used to find relevant literature. Research study keywords such as 'KM', 'KS', 'KMSs' and 'local government' were used as search terms. Municipal documents, such as annual reports, performance agreements, integrated development plans and policies, were also obtained from the appropriate departments and analysed to contribute to the results of the study.

\section{Strategies employed to ensure data quality and integrity}

Informal member checks were performed to establish credibility. After the interviews, the summarised notes were shared with participants via email to establish whether they were true reflections of what had been said during the interviews. A confirmability audit was conducted to minimise the influence of the researcher's judgement. The results were checked by a second researcher for bias and differences found in the analysis were discussed with the first researcher. Thus, participants' views were presented in a non-biased way, while every effort was made to ensure that their views were captured correctly (Mertens, 2005).

\section{Data analysis}

The qualitative data analysis process started after interviews were transcribed. The data collected through interviews with municipality managers and practitioners were analysed in a three-stage procedure suggested by Creswell (2014): preparing the data for analysis by transcribing, reducing the data into themes through a process of coding and representing the data. The interview data were analysed using NVivo qualitative data analysis computer software package. The first step was to create a new project using NVivo 11. Interview transcripts that were stored as MS Word documents were imported individually into the project. The datasets were systematically condensed into smaller units for analysis through the creation of categories and concepts derived from the data. The coding process was guided by different sections of the interview questionnaire that was structured using the themes from the literature reviewed (see Table 1).

\section{Ethical consideration}

Ethical approval was sought from the University Research Ethics Committee, and it was approved with the certificate reference number CIL021SNCO01. Ethics with regard to

TABLE 1: Example of quotes linked to main themes.

\begin{tabular}{|c|c|c|}
\hline Theme & Meaning of the theme & Quotes \\
\hline Organisational efficiency & $\begin{array}{l}\text { Knowledge transfer } \\
\text { improves organisational } \\
\text { efficiency }\end{array}$ & $\begin{array}{l}\text { 'Knowledge transfer can improve service delivery. The municipality is in the process of implementing applications that will } \\
\text { increase communication with its community.' } \\
\text { 'KM can improve competitive advantage through enhanced skills and the ability to solve problems quickly and as } \\
\text { they arise.' } \\
\text { 'Knowledge transfer creates new opportunities for the Municipality. New opportunities can arise from KM by employees } \\
\text { sharing innovative ideas to solve the problems of communities.' }\end{array}$ \\
\hline Motivation & $\begin{array}{l}\text { Knowledge cannot be } \\
\text { efficiently transferred if } \\
\text { employees are not } \\
\text { motivated to share it }\end{array}$ & $\begin{array}{l}\text { 'At the moment, sharing of knowledge does not contribute to positive performance appraisals. Knowledge is not included } \\
\text { in the key performance areas, but it should be there. We have been calling for that to be part of the appraisals.' } \\
\text { 'Staff are encouraged to pursue their studies which are fully paid by the Municipality.' }\end{array}$ \\
\hline Trust & $\begin{array}{l}\text { Employees are more likely } \\
\text { to share their knowledge if } \\
\text { there is trust }\end{array}$ & $\begin{array}{l}\text { 'Knowledge is largely hoarded at the higher levels of the organisational hierarchy.' } \\
\text { '... There seems to be a culture of knowledge hoarding in an attempt to augment personal importance or worth.' } \\
\text { 'In a political environment, knowledge transfer can be seen as a danger to power. Therefore, top management will be } \\
\text { reluctant to share knowledge.' }\end{array}$ \\
\hline Reciprocity & $\begin{array}{l}\text { Norm of reciprocity } \\
\text { increases knowledge-sharing } \\
\text { behaviour }\end{array}$ & $\begin{array}{l}\text { 'Although the Municipality formed the knowledge management section and has invested in systems for knowledge } \\
\text { transfer, on a human resources level information is not seamlessly transferred between managers and their subordinates. } \\
\text { There seems to be a culture of knowledge hoarding in an attempt to augment personal importance or worth.' }\end{array}$ \\
\hline Organisational culture & $\begin{array}{l}\text { Organisational culture } \\
\text { influences the employees' } \\
\text { attitude towards sharing } \\
\text { knowledge }\end{array}$ & $\begin{array}{l}\text { 'The culture of knowledge sharing has improved a great deal over the years and especially now that the KM unit falls } \\
\text { under the Office of the City Manager.' } \\
\text { 'The culture is not supportive as the hierarchical structures and bureaucratic management stifles any attempts at } \\
\text { openness and support within the organisation.' }\end{array}$ \\
\hline Top management support & $\begin{array}{l}\text { Top management support } \\
\text { significantly influences } \\
\text { knowledge-sharing attitude }\end{array}$ & $\begin{array}{l}\text { 'Although there has been a struggle, top management finally provided support.' } \\
\text { 'Knowledge is highly valued by top management because it plays a big role in the vision and direction of the organisation. } \\
\text { The top management should be the champions when it comes to building a culture of knowledge transfer.' } \\
\text { 'The top management also attempted to add KM as a key performance indicator for directors.' }\end{array}$ \\
\hline Organisational structure & $\begin{array}{l}\text { Flexible organisational } \\
\text { structures encourage the } \\
\text { sharing of knowledge and } \\
\text { collaboration }\end{array}$ & $\begin{array}{l}\text { 'Departmental location has added some value to KM. The department is now under the Office of the City Manager.' 'Now } \\
\text { top management knows what KM is; there is much support now compared to when it was under a line function.' } \\
\text { 'There is a structure in place that recognises knowledge as part of the organisation.' } \\
\text { 'Knowledge is not shared to the extent that the organisation can deliver quality services. Departments largely work in } \\
\text { silos with no real knowledge transfer.' }\end{array}$ \\
\hline Information technology & $\begin{array}{l}\text { Information technology plays } \\
\text { a decisive role in knowledge } \\
\text { transfer }\end{array}$ & $\begin{array}{l}\text { 'The implementation of SharePoint is still in progress. At the moment Internet is available where documents, such as } \\
\text { fiscal policies, are shared with the public.' } \\
\text { 'When it comes to skills needed to use knowledge-sharing technologies, interviews were conducted with the staff to } \\
\text { ascertain their perceptions with regard to the use of EDMS. Employees were found not knowing how to use the } \\
\text { technology although training had been offered to them.' } \\
\text { 'For the purposes of knowledge management, the corporate website is not interactive and has not been fully utilised.' } \\
\text { 'The KM portal on the intranet is not user-friendly, it is very difficult to access and utilise.' }\end{array}$ \\
\hline
\end{tabular}


participants' confidentiality, privacy and willingness to take part in the study were considered. Participants were not forced to participate in the study and were treated fairly and honestly during their participation. The data provided by the participants were accessible only to the researcher. Therefore, the data were kept safe and secure in a passwordprotected file on the researcher's computer. The collected data were used for this research study only and will not be used for any other purpose.

\section{Results}

A total of five participants aged between 30 and 50 years were interviewed. Two participants had recently joined the municipality, as they had worked less than a year in the department. One participant had worked between 3 and 5 years, while another had worked between 5 and 10 years. One participant had worked for the municipality for more than 10 years.

The qualitative data collected during the interviews were analysed using thematic analysis, an electronic qualitative data management system. Eight themes emerged as factors influencing KMSs. These eight themes were guided by the objective of this study: What factors will impact on KMSs to improve KT in BCMM? The eight identified themes include: (1) organisational efficiency, (2) motivation, (3) trust, (4) reciprocity, (5) organisational culture, (6) organisational structure, (7) top management support and (8) IT.

It was found that KS processes and systems can be challenged by individual, organisational, social, technical and political inter-organisational factors. Therefore, the determination of critical factors that impact employees' attitudes and intentions to share organisational knowledge could help improve organisational adoption of KMSs (AlBusaidi, 2013).

\section{Discussion}

The primary purpose of this study was to gain an in-depth understanding of the factors that impact on KMSs to improve the KT at BCMM. The study adopted STS theory that highlights the interrelationship between technological and social factors in understanding an organisation. The motivation behind examining problems concerning the information system using both the social and technical dimensions was to describe organisational aspects that are a combination of social and technological subsystems in the operational activities. The results, linked to the eight themes identified and indicated in the previous section, will be discussed under the corresponding quadrants of the STS theory.

\section{Structure}

Organisational culture affects the employees' attitudes towards knowledge sharing.
A staff member from the KM unit shared:

'The culture of knowledge sharing has improved a great deal over the years and especially now that the Knowledge Management unit falls under the Office of the City Manager. KM is getting the recognition it deserves and employees are beginning to comply.' (Participant A)

This meant that the structural position of the KM department in an organisation was crucial for KT. On the contrary, some participants suggested that the culture was not supportive of the hierarchy, and the bureaucratic management suppressed any attempts at openness and support in the organisational culture. This statement was similar to the findings of Gaffoor and Cloete (2010) in Stellenbosch where the municipality had a top-down, hierarchical structure that was not very conducive for KM efforts. The structure was bureaucratic in nature and was not responsive to changes being implemented.

\section{A staff member from the ICT department said:}

'The culture is not supportive as the hierarchical structures and bureaucratic management stifles any attempts at openness and support within the organisation.' (Participant D)

Another staff member from the ICT department said:

'The Municipality does not recognise knowledge as part of their asset base because there is no transfer of knowledge during succession or proper handover. It is likely that a new employee starts on a clean slate which is detrimental to the employee's job learning curve.' (Participant E)

Top management support significantly affects KS attitude. Shanshan (2013) believed that if employees have senior management support, their attitudes towards KT will be more positive, and they will feel more confident to share knowledge. Top managers' support of KM makes resource allocation to KT more feasible, which will encourage employees' optimistic attitudes towards the transfer of knowledge. Results demonstrated that BCMM has policies and procedures in place that support the transfer of knowledge, and these documents are accessible via the corporate intranet.

\section{A staff member from the ICT department shared:}

'The Municipality has policies and procedures that encourage the transfer of knowledge and they can be accessible on the intranet.' (Participant B)

The BCMM KM policy encouraged the sharing of knowledge, as its strategic objectives are to have every knowledge worker in the municipality collaborating and sharing knowledge on an electronic KM platform and in other forms, enabling knowledge optimisation and delivery in the organisation. The policy also specifies that its objective is to create a KS culture by changing personal and organisational behaviour to successfully implement and entrench $\mathrm{KM}$ in the municipality (Buffalo City Metropolitan Municipality, 2008).

Flexible organisational structures encourage the sharing of knowledge and collaboration. An organisational structure 
attempts to divide tasks among employees and arrange the coordination of their different task activities, and it is during this process that knowledge is created, transferred and shared (Cho \& Korte, 2014). Therefore, an organisational structure should be strategically designed to support knowledge activities because unintended structural barriers that might hinder knowledge creation and sharing may exist within the organisation. Results advised that there had been restructuring within the municipality. The relocation of the KM department had added value to the practice of KT.

A staff member from the KM unit shared:

'Departmental location has added some value to KM. The department is now under the Office of the City Manager.' (Participant A)

The BCMM head of the IKM, Research and Policy Department once indicated that the fact that the department was not at the required level was concerning as such a department was strategic and much needed to interact with various directors and senior leadership regarding knowledge and knowledge policies of the municipality (Norushe, 2013).

\section{People}

Knowledge cannot be efficiently transferred if employees are not motivated to share it. Knowledge has become a vital source of competitive advantage. It is critical therefore for municipalities to find ways to manage and motivate employees to share their knowledge. The municipality is encouraging its employees to pursue their studies through the provision of study bursaries.

A staff member from the ICT department shared:

'Staff are encouraged to pursue their studies which are fully paid by the Municipality.' (Participant C)

Results indicated that the sharing of knowledge in the municipality did not contribute to positive performance appraisals. Employees claimed that KS should be included in their key performance areas and be rewarded.

\section{A staff member from the KM unit shared:}

'At the moment, sharing of knowledge does not contribute to positive performance appraisals. Knowledge is not included in the key performance areas, but it should be there. We have been calling for that to be part of the appraisals.' (Participant A)

Employees are more likely to share their knowledge if there is trust, which has long been considered as one of the leading factors that contribute towards KT (Chai, Das, \& Rao, 2011) and is frequently recognised as a precursor to KT (Seba et al., 2012). Thus, trust is regarded as the focal point of every relationship within an organisation (Okyere-Kwakye \& Nor, 2011). Results revealed that there was a lack of trust within the municipality. Participants blamed top managers for hoarding important information.
A staff member from the KM unit shared:

'Knowledge is largely hoarded at the higher levels of the organisational hierarchy.' (Participant B)

A staff member from the ICT department claimed:

'... There seems to be a culture of knowledge hoarding in an attempt to augment personal importance or worth.' (Participant D)

A staff member from the ICT department said:

'In a political environment, knowledge transfer can be seen as a danger to power. Therefore top management will be reluctant to share knowledge.' (Participant E)

The norm of reciprocity increases KS behaviour. Employees improve their efforts at work to share knowledge when they expect that their work performance will be rewarded, and their success recognised (Liou, Chih, Yuan, \& Lin, 2016). Although BCMM had formed a KM department and invested its financial resources in KMSs, results indicated that employees are hoarding their knowledge.

A staff member from the ICT department said:

'Although the Municipality formed the knowledge management section and has invested in systems for knowledge transfer, on a human resources level information is not seamlessly transferred between managers and their subordinates.' (Participant C)

This is an indication that sharing of knowledge is not rewarded, and that the norm of reciprocity is absent. Two participants indicated that their efforts in KT were being recognised by the municipality, but they questioned the support being provided to carry this function.

A staff member from the KM unit shared:

'Although interviewees agree that there is some recognition, they ask if they are capacitated enough to carry this function of knowledge transfer.' (Participant B)

A staff member from the ICT department said:

'The lack of communication can be blamed by some project drivers or project managers who fail to communicate their initiatives and face challenges when the technology needs to be used by employees.' (Participant C)

\section{Technology}

Information technology plays a positive role in KT. Information systems are beneficial tools in KT, and technologies, such as knowledge repositories, decision support systems, intranets and social networking sites, afford opportunities for communication and transfer of knowledge (Seba et al., 2012). Results indicated that the municipality was at a stage of implementing SharePoint as its KM portal.

A staff member from the ICT department said:

'The implementation of SharePoint is still in progress. At the moment the Internet is available where documents, such as finance policies, are shared with the public.' (Participant C) 
An electronic document management system (EDMS) had previously been used by the municipality, and it was now being replaced by SharePoint. Issues mentioned by participants which led to the cancellation of the EDMS were the user uptake, because of lack of IT skills, and cost.

\section{A staff member from the ICT department said:}

'Systems for knowledge sharing are not really complicated, but the platform that was created was a matter of costing licensing. The Municipality had an EDMS tool for documenting that was deployed but only for 200 users. It was too expensive as it was costing plus minus 2 million and we are now deploying SharePoint which is open for everyone and we are not going to have licensing issues.' (Participant C)

\section{Tasks}

Knowledge transfer improves organisational efficiency. Good $\mathrm{KM}$ in an organisation increases efficiency in business operations by increasing the effectiveness of ethical decision-making, appropriate planning, increasing performance and optimising the operation time (Kuras \& Kuras, 2015). To ascertain whether BCMM employees understood the benefits of $\mathrm{KT}$, they were asked if they agreed that the benefits include improved service delivery, decision-making and quality; reduced costs; enhanced customer focus; better developed employees; improved competitive advantage, new opportunities for the municipality; and improved work process in the municipality. Results indicated that BCMM employees understood the vital role played by KT in an organisation.

A staff member from the ICT department said:

'Knowledge transfer can improve service delivery. The Municipality is in the process of implementing applications that will increase communication with its community.' (Participant C)

A staff member from the KM unit shared:

'KM can improve competitive advantage through enhanced skills and the ability to solve problems quickly and as they arise.' (Participant B)

A staff member from the KM unit shared:

'Knowledge transfer creates new opportunities for the Municipality. New opportunities can arise from KM by employees sharing innovative ideas to solve the problems of communities.' (Participant A)

They understood that through KT, innovative ideas can be shared to solve problems experienced by the served communities and that KT can improve service delivery.

\section{Limitations}

The study was confined to collecting data from senior and middle managers in the BCMM. These five staff members who were interviewed for the study were found to be knowledgeable about the research topic and could contribute in a meaningful way to the research problem. However, because only five staff members were interviewed, the results of this study cannot be generalised to all municipalities; therefore, it is recommended that in future studies, the data collection is extended to include more municipalities and participants. This would ensure a more comprehensive assessment of the views and perceptions towards KT practices at BCMM.

\section{Conclusion}

The study found that the municipality's bureaucratic organisational structure hampers any attempts at KS. It was also found that information is not seamlessly transferred between managers and their subordinates. The municipality has a culture of knowledge hoarding in attempts to augment personal importance or worth. The study also found that the culture of KS had improved a great deal over the years and especially because the KM unit was placed under the Office of the City Manager. Knowledge management is getting the recognition it deserves, and employees were beginning to comply. This means that the structural position of the KM department in an organisation is crucial for KT.

The researcher therefore recommends that BCMM must ensure that KT practices and initiatives are fully supported and promoted by top management. This would confidently ensure that sufficient resources to support KT would be allocated. To solve the KT problems, KM needs to be aligned with organisational strategy. Official KM strategies need to be developed and aligned with the organisational strategy to ensure that top management makes and shares a vision on $\mathrm{KT}$ and continually plans for realising the agreed-upon KT objectives. Buffalo City Metropolitan Municipality top managers must recognise the shortcomings of bureaucratic structures and acknowledge that they slow the processes and limit the information flow. The reporting procedures in current structures consume excessive amounts of time in order for knowledge to filter through every level of the municipality. Knowledge transfer succeeds with structures that support ease of information flow, with fewer boundaries between divisions.

Buffalo City Metropolitan Municipality's most valuable intellectual resources are entrenched in the minds of the employees; KT can be achieved only through a passion that stimulates the deepest parts of the employees' minds (Egbu, Wood, \& Egbu, 2010). Therefore, if the municipal employees are not motivated to share their knowledge, no amount of investment, infrastructure and technological intervention can make KT effective. Training is critical for effective KT among the municipality employees. Through training, employees will have a better understanding of the concept of KT. Buffalo City Metropolitan Municipality employees need to be educated in using a KMS and any other technological tool that can be useful in sharing of knowledge.

Buffalo City Metropolitan Municipality should invest in a comprehensive technological infrastructure, such as communication systems and IT, for the purpose of KT. Technologies, such as chat rooms, telephone and video 
conference, can be used to transfer tacit knowledge (Sedighi \& Zand, 2012). Factors, such as ease of use, simplicity of the technology, connection with knowledge content and standardisation of a knowledge structure, and adaptability to the needs of users, have to be considered when municipalities develop KMSs (Margilaj \& Bello, 2015). The key for BCMM is to understand how technology is developed and how is it aligned to organisational strategy and knowledge processes. This can play a critical role in managing and supporting the municipality's KT activities.

\section{Acknowledgements}

The authors would like to thank the employees of the Buffalo City Metropolitan Municipality for participating in this study.

\section{Competing interests}

The authors declare that they have no financial or personal relationships that may have inappropriately influenced them in writing this article.

\section{Authors' contributions}

S.N. conceptualised and wrote the study under the supervision of L.C.

\section{Funding information}

This research received no specific grant from any funding agency in the public, commercial, or not-for-profit sectors.

\section{Data availability statement}

Data are available upon request.

\section{Disclaimer}

The views and opinions expressed in this article are those of the authors and do not necessarily reflect the official policy or position of the University of Fort Hare.

\section{References}

Al-Busaidi, K.A. (2013). A framework of critical factors to knowledge workers' adoption of inter-organisational knowledge sharing systems. Journal of Organisational Knowledge Management, 2013(2013), 11. https://doi.org/10.5171/2013.496419

Amayah, A.T. (2013). Determinants of knowledge sharing in a public sector organisation. Journal of Knowledge Management, 17(3), 454-471. https://doi. org/10.1108/JKM-11-2012-0369

Ansari, M., Youshanlouei, H.R., \& Mood, M.M. (2012). A conceptual model for success in implementing knowledge management: A case study in Tehran Municipality. Journal of Service Science and Management, 5(2), 212-222. https://doi. org/10.4236/jssm.2012.52026

Assegaff, S., \& Hussin, A.R.C. (2012). Review of knowledge management systems as sociotechnical system. International Journal of Computer Science Issues, 9(5), 129-134.

Becerra-Fernandez, I., \& Sabherwal, R. (2010). Knowledge management: Systems and processes. New York: Sharpe.

Buffalo City Metropolitan Municipality. (2008). Knowledge management policy. East London. Retrieved from https://www.buffalocitymetro.gov.za/Documents

Cartelli, A. (2007). Socio-technical theory and knowledge construction: Towards new pedagogical paradigms? Issues in Informing Science and Information Technology, 4, 2-14.

Chai, S., Das, S., \& Rao, H.R. (2011). Factors affecting Bloggers' knowledge sharing: An investigation across gender. Journal of Management Information Systems, 28(3), 309-342. https://doi.org/10.2753/MIS0742-1222280309
Cho, T., \& Korte, R. (2014). Managing knowledge performance: Testing the components of a knowledge management system on organisational performance. Asia Pacific Education Review, 15(2), 313-327. https://doi.org/10.1007/s12564-014-9333-x

Creswell, J.W. (2014). Research design: Qualitative, quantitative, and mixed methods approaches (4th edn.). Newbury Park, CA: Sage.

De Vos, A.S., Strydom, H., Fouche, C.B., \& Delport, C.S.L. (2011). Research at grassroots: For the social sciences and human service professions (4th edn.). Pretoria: Van Schaik Publishers.

Deverell, A.C., \& Burnett, S. (2012). Need-to-know cultures: An investigation into intra-organisational and extra-organisational knowledge sharing cultures in local government in the UK. Knowledge and Process Management, 19(3), 131-141. https://doi.org/10.1002/kpm

Dikotla, M.A., Mahlatji, M.R., Makgahlela, L.A., \& Africa, S. (2014). Knowledge management for the improvement of service delivery in South Africa's management for the improvement of service delivery in
municipalities. Journal of Public Administration, 49(3), 847-859.

Duan, Y., Nie, W., \& Coakes, E. (2010). Identifying key factors affecting transnational knowledge transfer. Information \& Management, 47(7-8), 356-363. https://doi. org/10.1016/j.im.2010.08.003

Egbu, J.U., Wood, G., \& Egbu, C.O. (2010). Critical success factors associated with effective knowledge sharing in the provision of floating support services in sheltered housing for the elderly. In C. Egbu (Ed.), Proceedings of the 26th Annual ARCOM Conference (pp. 849-857). 6-8 September 2010. Leeds: Association of Researchers in Construction Management.

Etherington, S. (2013). Knowledge sharing cultures needed to transform our services. Retrieved from https://www.theinformationdaily.com/2013/04/29/knowledgesharing-cultures-needed-to-transform-our-services

Gaffoor, S. (2008). Assessing readiness for the implementation of knowledge management in local governments: The case of Stellenbosch Municipality. Stellenbosch: Stellenbosch University.

Gaffoor, S., \& Cloete, F. (2010). Knowledge management in local government: The case of Stellenbosch Municipality. SA Journal of Information Management, 12(1), 1-7. https://doi.org/10.4102/sajim.v12i1.422

Greco, M., Grimaldi, M., \& Hanandi, M. (2013). How to select knowledge management systems: A framework to support managers regular paper. International Journal of Engineering Business Management, 5(1), 1-11. https://doi.org/10.5772/56003

Kathiravelu, S.R., Mansor, N.N.A., \& Kenny, K. (2013). Factors influencing knowledge sharing behavior (KSB) among employees of public services in Malaysia. International Journal of Academic Research in Economics and Management Sciences, 2(3), 107-120.

Kitchin, F., Ovens, W., \& Turpin, M. (2013). Capacity building through knowledge management: A toolkit for South African municipalities. Johannesburg: South African Cities Network \& SALGA.

Kuras, M., \& Kuras, P. (2015). The process of knowledge sharing in local government units. In The 2015 WEI International Academic Conference Proceedings (pp. 155-162). Vienna: The West East Institute.

Lee, H.S., \& Hong, A.S. (2014). Factors affecting hospital employees' knowledge sharing intention and behavior, and innovation behavior. Osong Public Health and Research Perspectives, 5(3), 148-155. https://doi.org/10.1016/j.phrp.2014.04.006

Liou, D.-K., Chih, W.-H., Yuan, C.-Y., \& Lin, C.-Y. (2016). The study of the antecedents of knowledge sharing behavior. Internet Research, 26(4), 845-868. https://doi. org/10.1108/IntR-10-2014-0256

Mannie, A., Van Niekerk, H. J., \& Adendorff, C. M. (2013). Significant factors for enabling knowledge sharing between government agencies within South Africa. SA Journal of Information Management, 15(2), 1-9. https://doi.org/10.4102/ sajim.v15i2.569

Margilaj, E., \& Bello, K. (2015). Critical success factors of knowledge management in Albania business organizations. European Journal of Research \& Reflection in Management Sciences, 3(2), 15-24. https://doi.org/10.1108/09555340610651820

Mertens, D.M. (2005). Research and evaluationin education and psychology: Integrating diversity with quantitative, qualitative, and mixed methods. London: Sage.

MILE. (2010). eThekwini knowledge strategy and implementation plan 2010-2014. Durban: MILE.

Mohamed, O. (2014). Knowledge sharing initiatives in local authorities in Malaysia. Manchester: University of Salford.

Mothamaha, W.B., \& Govender, K.K. (2014). Exploring the role of knowledge management in improving service operations: The case of the select departments in the City of Johannesburg, South Africa. International Journal of Managerial Studies and Research, 2(5), 1-8.

Munzhelele, T. (2012). Knowledge management and service delivery: A knowledge management model for the housing sector. Stellenbosch: Stellenbosch University.

Norushe, T. (2013). Basic knowledge training for councillors and officials [PowerPoint Slides]. KMRG quarterly meeting. 14-15 March 2013. Durban. Retrieved from https://www.google.com/url?sa=t\& $r c t=j \& q=\& e s r c=s \&$ source $=w e b \& c d=1 \& v e d=2$ ahUKEwjAv76VmP7nAhWGsBQKHb-hC1cQFjAAegQIARAB\&url=https\%3A\%2F\%2 Fwww.salga.org.za\%2FDocuments\%2FMunicipalities\%2FGuidelines\%2520for\%2 520 Municipalities\%2FGuideline-Document--On-The-Roles-and-Responsibilitiesof-Councillors-and-Officials-(2)-(1st-Draft)_.pdf\&usg=AOVVaw1P1JuXLXRunnI9Nb uBThRv

Okyere-Kwakye, E., \& Nor, M.K. (2011). Individual factors and knowledge sharing. American Journal of Economics and Business Administration, 3(1), 66-72.

Ondari-Okemwa, E., \& Smith, J.G. (2009). The role of knowledge management in enhancing government service-delivery in Kenya. SA Journal of Libraries \& Information Science, 75(1), 28-39. https://doi.org/10.7553/75-1-1271

Ramdhania, Y.P. (2012). What makes employee willing to share knowledge via Intranet? Enschede: University of Twente. 
Sajeva, S. (2010). The analysis of key elements of socio-technical knowledge management system. Economics and Management, 15, 765-774. Retrieved from management system. Economics and Management, 15, 765-774. Retrieved fror
https://www.ktu.lt/lt/mokslas/zurnalai/ekovad/15/1822-6515-2010-765.pdf

SALGA. (2015). Knowledge management in South African cities. In KNOW.vation: Sharing municipal knowledge, innovation \& excellence (pp. 15-22). Pretoria: SALGA

Schutte, N., \& Barkhuizen, N. (2014). Knowledge management and sharing in local government: A social identity theory perspective. The Electronic Journal of Knowledge Management, 13(2), 130-141.

Seba, I., Rowley, J., \& Lambert, S. (2012). Factors affecting attitudes and intentions towards knowledge sharing in the Dubai Police Force. International Journal of Information Management, 32(4), 372-380. https://doi.org/10.1016/j.ijinfomgt.2011.12.003

Sedighi, M., \& Zand, F. (2012). Knowledge management: Review of the critical success factors and development of a conceptual classification model. In 10th Internationa Conference on ICT and Knowledge Engineering 2012 (pp. 1-9). Siam University, Bangkok: IEEE.

Shanshan, S. (2013). An integrated model on factors influencing knowledge sharing. International Journal of Digital Content Technology and Its Applications, $7(9)$, 66-74. https://doi.org/10.4156/jdcta.vol7.issue9.9

Tamjidyamcholo, A., Bin Baba, M.S., Tamjid, H., \& Gholipour, R. (2013). Information security - Professional perceptions of knowledge-sharing intention under selfsecurity - Professional perceptions of knowledge-sharing intention under self223-232. https://doi.org/10.1016/j.compedu.2013.05.010

Tan, C.N., \& Noor, S.M. (2013). Knowledge management enablers, knowledge sharing and research collaboration: A study of knowledge management at research universities in Malaysia. Asian Journal of Technology Innovation, 21(2), 251-276. https://doi.org/10.1080/19761597.2013.866314
Teimouri, H., Emami, S., \& Hamidipour, S. (2011). Studying the effective organisational factors on knowledge sharing between employees of governmental organisations in Isfahan province, Iran. Interdisciplinary Journal of Contemporary Research in in Isfahan province, Iran.
Business, 3(5), 921-931.

Theriou, N., Maditinos, D., \& Theriou, G. (2011). Knowledge management enabler factors and firm performance: an empirical research of the Greek medium and large firms. European Research Studies Journal, 14(2), 97-134.

Van Der Meer, R. (2014). Knowledge sharing in inter-organisational collaborations. Geelong: Deakin University.

Wang, M., Lee, D., \& Lim, K. (2009). Knowledge management systems diffusion in Chinese enterprises: A multi-stage approach with the technology-organisationenvironment framework. Journal of Global Information Management, 17(1), 70-84. https://doi.org/10.4018/jgim.2009010104

Wang, S., \& Noe, R. A. (2010). Knowledge sharing: A review and directions for future research. Human Resource Management Review, 20(2), 115-131. https://doi. org/10.1016/j.hrmr.2009.10.001

Wang, S., Noe, R.A., \& Wang, Z. (2014). Motivating knowledge sharing in knowledge management systems: A quasi-field experiment. Journal of Management, 40(4) 978-1009. https://doi.org/10.1177/0149206311412192

Yin, R.K. (2014). Case study research: Design and methods (5th edn.). Los Angeles, CA: Sage.

Zhang, X., Vogel, D.R., \& Zhou, Z. (2012). Effects of information technologies, department characteristics and individual roles on improving knowledge sharing visibility: A qualitative case study. Behaviour \& Information Technology, 31(11) 1-15. https://doi.org/10.1080/0144929X.2012.687770 